\title{
1 Using Hyperspectral Imaging to reveal a hidden precolonial Mesoamerican codex
}

${ }_{3}$ Ludo Snijders $^{\mathrm{a}^{*}}$, Tim Zaman ${ }^{\mathrm{b}}$, David Howell ${ }^{\mathrm{c}}$

\author{
${ }^{a}$ Faculty of Archaeology, Leiden University \\ ${ }^{b}$ Faculty of Applied Sciences, Delft University \\ c Bodleian Libraries, University of Oxford \\ * Corresponding author: I.snijders@arch.leidenuniv.nl
}

Keywords: hyperspectral, imaging, Mesoamerica, writing, palimpsest, manuscript

\begin{abstract}
Hyperspectral imaging is applied to a Mixtec codex in order to reveal an abundance of never before seen pictographic scenes hidden underneath a layer of gypsum and chalk gesso. Because of the organic nature of these paints, no other technique has been able to reveal them in a non-invasive manner. The results thus far indicate that the covered text contains unique genealogic information which may prove invaluable for the interpretation of archaeological remains from southern Mexico.
\end{abstract}

Less than twenty books are still in existence today that were made in the Americas before the conquest by the Europeans. All of these are from the area known to researchers as Mesoamerica. Of these, five books come from the Mixtec area in the present-day Mexican state of Oaxaca. One of these five, the codex Añute or MS. Arch. Selden. A. 2., has been known to be a palimpsest for over fifty years (Dark and Plesters, 1958a). The material from which these Mixtec codices were made has so far thwarted all attempts to recover the hidden pictographic texts in a noninvasive manner. The Mixtec codices are made on long strips of leather attached end-to-end to form the substrate of the book (Maldonado Alvarado and Maldonado Alvarado, 2004). The nature of this leather has only been tentatively identified on one of the codices, the codex Iya Nacuaa or Colombino-Becker, where it seems to be made of pronghorn skin (Alvarez, 1966). The leather substrate was folded like a concertina and covered on both sides with a layer of white gesso. The resulting blank book has rigid white pages, which could be used on one or on both sides. The writing system of the Mixtec and other central and southern Mesoamerican peoples was pictographic (Jansen and Pérez Jiménez, 2011, Boone, 2000). Thus complex ideas were written by drawing pictures conforming to certain conventions (see Figure 1). These pictures were made with paints in different colours, all of which have been shown to be organic (Dark and Plesters, 1958a, Zetina, et al., 2011, Miliani, et al., 2012, Buti, 2012). The Mixtec books are all genealogic in content, representing the deeds of a long line of ancestors, often going back in time hundreds of years (Jansen and Pérez Jiménez, 2011). Since many of the places that are mentioned in these codices can be linked geographically to archaeological sites (Smith, 1973), the narrative encoded in these books is of clear importance for the archaeology of the region. The marriage alliances, armed conflicts and ritual practices depicted in

52 the codices give insight into the geopolitical and socioreligious 53 relations between different archaeological sites (Byland and Pohl, 54 1994, Joyce, et al., 2004). In the case of the codex Añute, an old 55 document of fifteen pages long was reused to make the known 56 text. A strip of leather was added to these fifteen pages and the 57 whole was covered with a new layer of gesso, to create a twenty 58 page long document. The challenge for recovery of these texts 59 thus lies in the localisation and imaging of organic paints 60

61

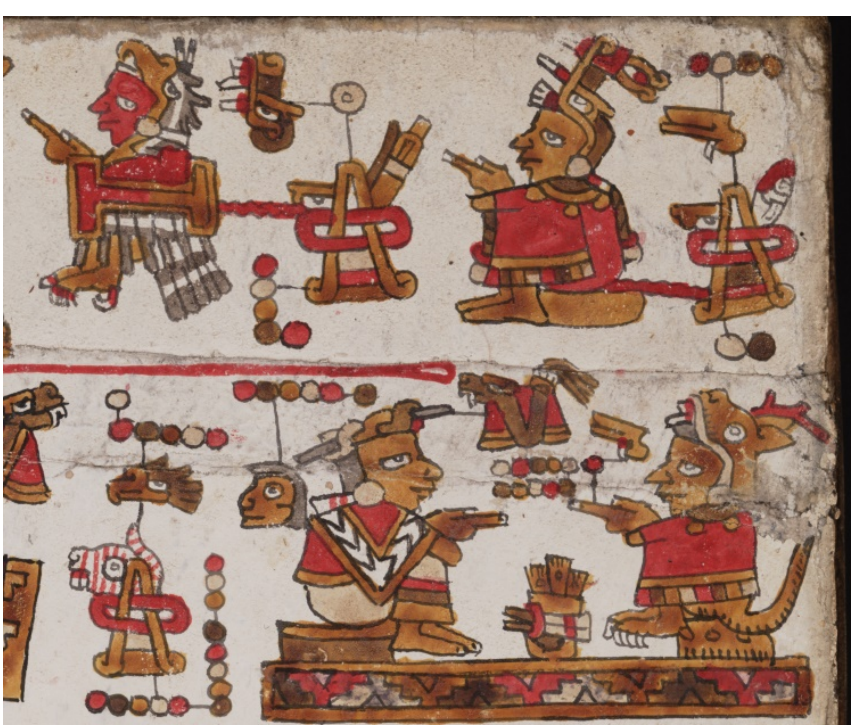

Figure 1. Example of pictographic writing. This scene depicts a marriage (bottom) and the two children that came from this marriage (top, notice the red umbilical cords) on Codex Añute page 8 recto. Courtesy of the Bodleian Libraries, University of Oxford, MS. Arch. Selden. A. 2. 


\section{Research Background}

\subsection{Earliest investigation (1952-1958)}

Interest in these images started in the 1950's when the Mexican archaeologist Alfonso Caso observed traces of the hidden images through the cracks in the gesso layer on the reverse of the document, and understood their potential importance (Dark and Plesters, 1958a). At his request the codex underwent a series of investigations between 1952 and 1958 to try and uncover the hidden images (Dark and Plesters, 1958b). As both x-ray and infrared imaging failed to produce the desired results, the investigations involved the physical removal of the covering gesso on selected areas, including page 11 verso in its entirety, to uncover the palimpsest (see Figure 2). It has to be noted here that the pages of the palimpsest have been numbered based on the pages of the front. The codex on the front is read with the document held vertically, though to read the covered text on the reverse side, the books needs to be held horizontally. As a result page 11 is located to the left of page 10 . This does not reflect any reconstructed reading order. In fact, not much could be made of these uncovered images at that time, as image processing techniques did not exist. The only information that was recovered was the general line structure of the text, the location of some individual, and the fact that this also seemed to be a Mixtec historical text (Caso, 1964). The result was that the palimpsest was considered to be no longer recoverable and that further investigation was not warranted.

\subsection{Present research (2012-2016)}

New technologies developed over the past sixty years call the unrecoverable nature of the palimpsest into question. A collaboration between the Universities of Leiden and Delft (The Netherlands) and the Bodleian Library of the University of Oxford resulted in a research project aimed at recovering more information about these hidden texts. A series of techniques was developed and applied to the codex between 2012 and 2016 to record the images visible at the surface and to try and make the covered images visible. The techniques applied were Infrared imaging, RTI Imaging (see Earl, et al., 2010), Photothermal Tomography, and Hyperspectral Imaging (see Grahn and Geladi, 2007). Infrared Imaging was applied to check the results of the 1950 's research team. A major difference was that no substance could be applied to the surface to make it easier for infrared radiation to penetrate the surface, as had been done in the 1950's with xylene (Dark and Plesters, 1958b). Thus the new Infrared photos did not reveal as much as the older pictures, making these photographs still an important source of information about subsurface traces of carbon. Photothermal Tomography (PTT) was developed as a method of making subsurface colours visible, by measuring the thermal energy produced when colours absorb light. However Infrared photography combined with the newly developed technique showed that the internal structure of the codex is full of pockets of air. As a result the PTT cannot be successfully applied to this object, as the transmission of thermal energy is disrupted by the internal faults. This also explains why the Infrared photos made during the 1950's investigation show more traces of carbon, as the xylene that was used to increase the refractive index filled up the pockets of air, allowing for better transmission of infrared radiation. Because of this difficulty in penetrating the surface for infrared radiation, and the organic nature of the paints, many analytical techniques are inapplicable. Hyperspectral imaging was applied with the idea that it would record the colours of the figures that were physically uncovered due to wear, or the intervention of the 1950's. Besides these methods for recording images, RTI imaging was used to record surface texture. Although RTI does not record subsurface information, it is useful to have information on surface texture as this can cast shadows that in two-dimensional images get easily misinterpreted as part of the design.

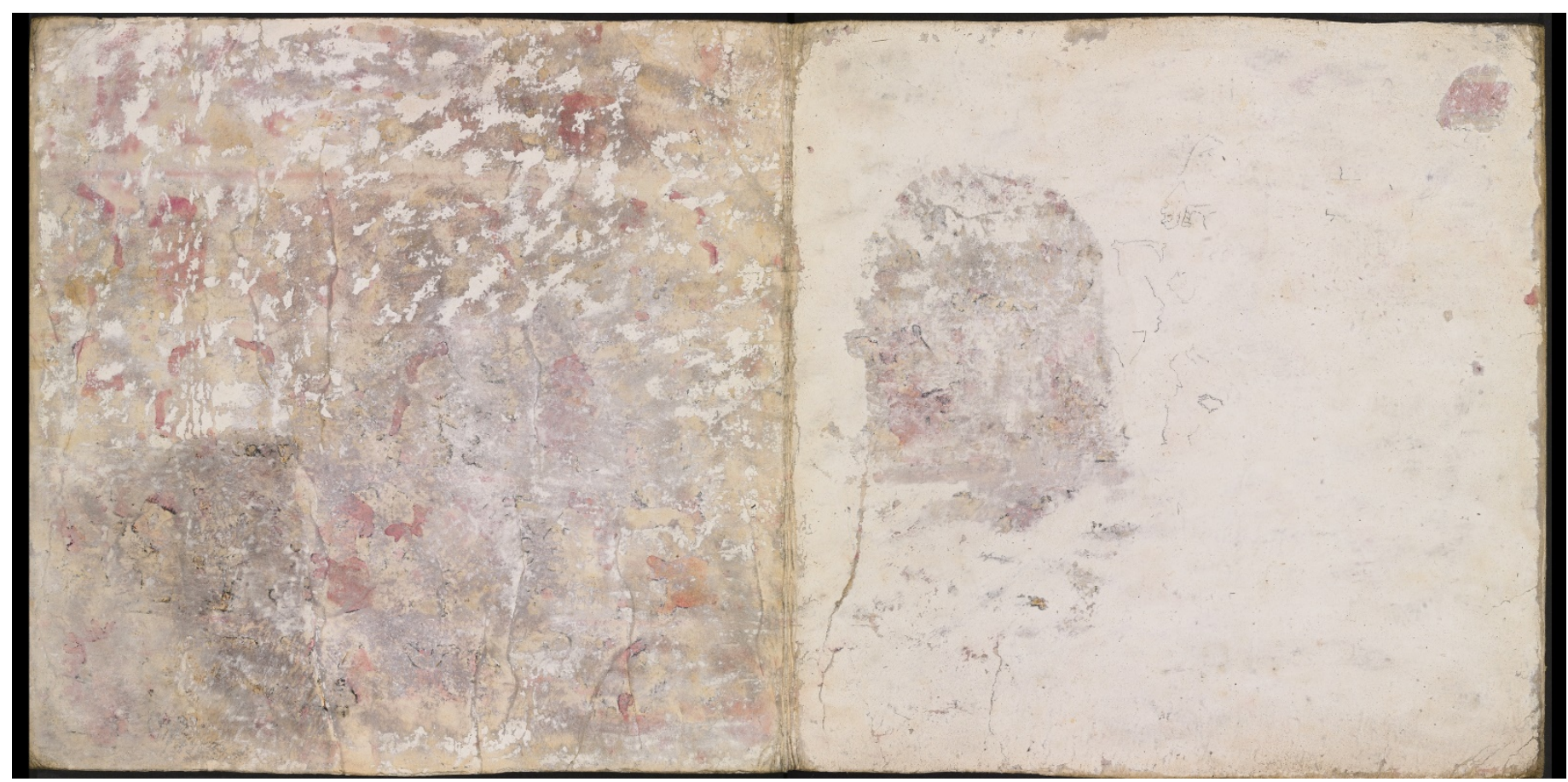

Figure 2. Pages 11 and 10 verso of codex Añute showing the areas which were physically uncovered during the 1950's investigation. (C) The Bodleian Libraries, University of Oxford, MS. Arch. Selden. A. 2. 


\section{Hyperspectral Imaging}

\subsection{Image acquisition}

The codex was scanned during the investigation of the DelftLeiden team in 2015 using a hyperspectral imaging device newly acquired by the Bodleian Library. Time constraints did not allow a full scan of the document to be made. Therefore pages were selected based on the idea that the scans would aid the interpretation of the already physically uncovered sections. Thus on the verso side pages $11,10,7-5,3$ and 1 were scanned. Since more time was available, pages 1 and 2 of the recto side were also scanned. The set-up used was a line scanner (Hyperspec ${ }^{\circledR}$ VNIR ESeries) which measured the spectral response between 380 and $1000 \mathrm{~nm}$ in 972 steps for each of the 1600 pixels in the scanning line. This can also be conceptualised as a stack of 972 grayscale images representing the relative reflectance of the surface for each section of the spectrum. This set-up uses a Quartz Tungsten Halogen (QTH) light source. A filter was installed in front of the light source to block out any potentially damaging UV radiation. The effective range of the device was thus between $400 \mathrm{~nm}$ and $1000 \mathrm{~nm}$.

\subsection{Image analysis}

The file size and complexity of the Hyperspectral images means that specialized software is needed for its processing. Exelis Envi ${ }^{\circledR}$ provides a set of tools that allowed these recordings to be interpreted. The first step was to reduce the amount of noise in the data by performing a Minimum Noise Fraction Transform (MNF). This performs a Principal Components Analysis (PCA) (Jolliffe, 2002) and orders the resulting series of bands ranked at decreasing two-dimensional coherence. By discarding the set of MNF bands that contain only noise, the total size of the dataset is reduced and the signal-to noise ratio improved. An Independent Component Analysis (ICA) (Stone, 2004) on the resultant inverse MNF data was used to separate the signal of the different components. The advantage of ICA over PCA for this data is that ICA is better able to detect components that are only present in a small section of the total analysed image, because it assumes that

the data is made up of independent components and is nonnormal. Each ICA signal can again be depicted as a single grayscale image representing the distribution of the specific colour. When performing the ICA, a number of parameters can be defined. Because of the low number of expected components and the small percentage of the surface covered by these features, the IC threshold needed to be as low as possible $\left(10^{-8}\right)$, while the maximum number of iterations and stabilization iterations needed to be high (5000). In each ICA twenty components were generated. This was enough to encompass all the different components, as the last ten bands contained only noise.

In order to obtain an overview of the general composition, the whole page can be analysed at once. What is made most clearly visible with this is the red paint. The reason for this is that the spectral response of the cochineal red is clearly distinguishable from the white gesso and the leather (see Figure 3). Pages that have been partially uncovered needed to be analysed in two steps: one for the uncovered parts; and another for the still covered areas. This is necessary as the signal from the covered areas will otherwise be obscured by the signal from the uncovered sections.

To avoid that yellow features disappear as noise in the white background, a subset of the total image can be analysed where a relative abundance of yellow is expected, based on already discovered features. Because now a relatively high amount of pixels have the yellow signal, it becomes easier to distinguish from the sections that only contain white gesso. It has been empirically found that in these cases ICA still yields better results than PCA. Interpretation of these results requires combining the different ICA bands and trying to redraw the outlines of individual features. This is a complex task that requires knowledge of the Mixtec writing style and conventions. One of the main difficulties is that each Mesoamerican scribe had a distinct hand. Therefore each document looks different and although there are general rules for writing, an understanding of the style of the scribe is needed to be able to reconstruct more complex figures. For this the sections that were laid bare by the earlier investigation are essential.
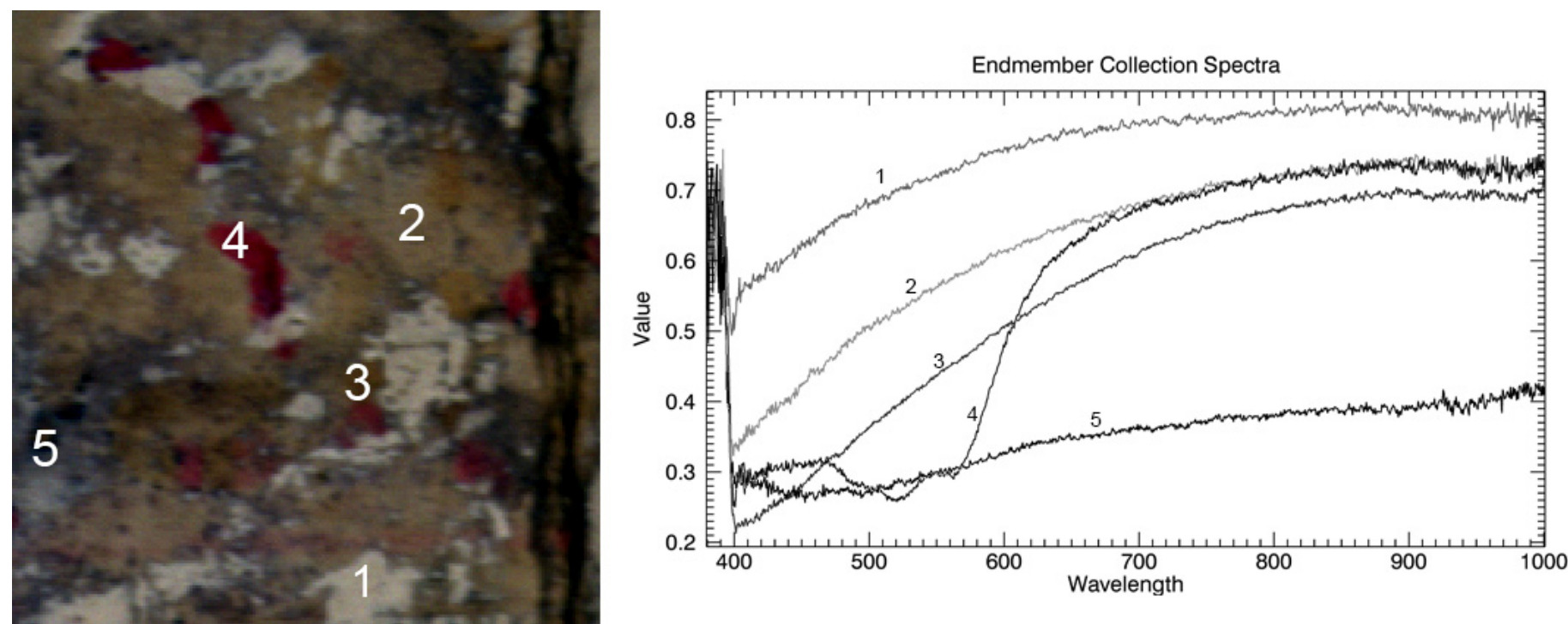


\section{Results}

\subsection{Reconstruction of page 11 verso}

The physically uncovered page 11 verso formed an important starting point for the reconstruction of the palimpsest. Because the images are visible at the surface, the hyperspectral imaging data can here be supported by regular photography, Infrared photography and RTI imaging. In regular photographs of the surface, multiple colours can already be distinguished. Besides the traces of black outlines these are: red, yellow, and orange. This is not surprising, as the other colours used in the codices, i.e. greens and blues, are generally less stable and disappear over time. On the recto side of the codex Añute, blue has deteriorated to light grey; and green, which is a mixture of yellow and blue, has become brown (see facsimile in Jansen and Pérez Jiménez, 2007). A similar pattern of discoloration can be seen in the codex Ñu

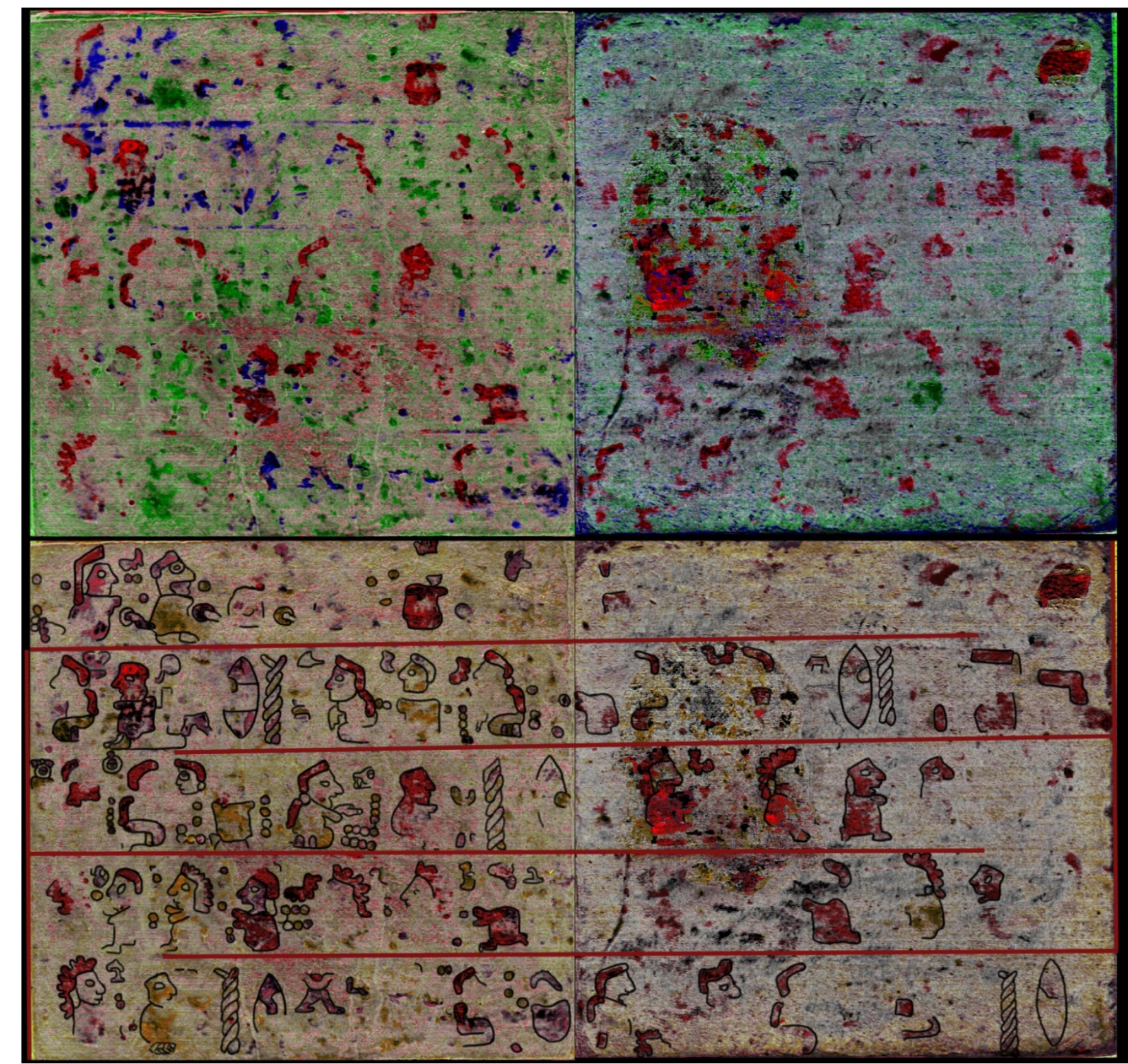

Tnoo-Ndisi Nuu (Bodley), although here the red has also started to deteriorate and detach from the surface (cf. Jansen and Pérez Jiménez, 2005). Close study of the Infrared photos made during the 1950's investigation showed that the black outlines were already severely worn when the codex was covered with a new gesso layer. The lack of black outlines and the deterioration of the colours indicates that the document was not in pristine condition when it was covered with gesso. What is visible at the surface of page 11 are the stains that the natural dye, from which the paint was made, had left on the leather substrate. Because the leather is also yellow, distinguishing yellow and orange paint from the leather background is difficult when studying the original document or regular photographs. Such subtle differences in colour can be made visible using hyperspectral imaging. Thus traces of the original design could be distinguished from the leather where none are visible to the naked eye.

Figure 4. Three ICA bands are combined into an RGB image of pages 11 and 10 (above), reconstruction of these two pages based on this information (below). Compare also with Figure 2. 
Page 11 verso functions as a type of style guide that gives information about the general way of drawing of this particular scribe. It allows for the reconstruction of certain regularities which are essential for the interpretation of the completely covered areas. Although there are not many of these codices, this work does not have to be interpreted in complete isolation. For example the characters that are sitting on their knees can, because of conventions recognised in the other books, be understood to be female (cf. Anders, et al., 1992). On page 11 verso a total of at least 27 people can be seen. The figures on the top row can be seen to have an umbilical cord attached to their behind (c.f. Figure 1). Following Mixtec writing convention (see Jansen and Pérez Jiménez, 2011) this makes them siblings, born from a pair that is presumably depicted on the top right of page 12. Although this pair has not yet been recovered and thus not much more can be interpreted from this text, the orientation of these children is indicative of the reading order of the document. In general these compositions are depicted in such a way that the children are depicted after and facing away from the parents. This would mean that the codex is read from left to right. In the Mixtec codices figures are not distinguishable by facial features. Individuals are identified by calendar names, reflecting the day in the 260-day Mesoamerican calendar on which they are born. These 260 days are created by combining one of the twenty possible day signs with a number (1-13), depicted as a series of dots. Identification of the people located on page 11 is made very difficult as nowhere a clear combination of numeral and calendar sign is identified. Besides calendar names, individuals can also be given personal names. These are often incorporated in the dress of the depicted figure, or drawn next to them. These names are more variable than the calendar names, though men are often given names related to strong fearsome animals, while women often get names after precious objects. On lines 2, 3, and 5, the same combination of visual elements (glyphs) can be found. A twisted cord combined with a large glyph representing a flint knife likely forms a personal name. The significance of this motif is discussed in section 5.1 .

\subsection{Images from sections still covered with gesso}

The difficulty of distinguishing yellow paint from white gesso and leather substrate is obviously more severe in the sections still completely covered in gesso. Recovering the red paint is still relatively easy however. These red sections can be partially interpreted, because of the general style established on page 11 . Thus on the lower section of page 10 two women can be seen, who can be distinguished by virtue of the red section of the top of their head and on their back. The red section on their head may be either part of their hair or a headdress, while the section on their back represents the mantle known as the quechquemit/ that women are generally depicted in. It can also be seen that the reading lines already seen on page 11 , continue as expected on page 10 and divide the two pages in such a way that both pages need to be read together. The reading of page 9 and 8 is expected to start at the bottom left and continue to the upper right.

On the scanned pages 7-5 this reading order continues. Another series of people have been located, though these cannot yet be identified. Almost all of these figures are facing in the same direction. Such long lists of figures all facing one direction are rare in the known codices. More detailed analysis is required to determine the nature of this section. One striking feature can already be distinguished. On the bottom of page 6 a number of persons can be seen walking, either with sticks or spears in their hand. This is a rather common motif also found in the other codices (see Figure 5). This scene thus either represents a military expedition or persons travelling from one place to the next. The place they are going to is expected on the bottom of page 5 , though this is difficult to reconstruct as this section is severely damaged.

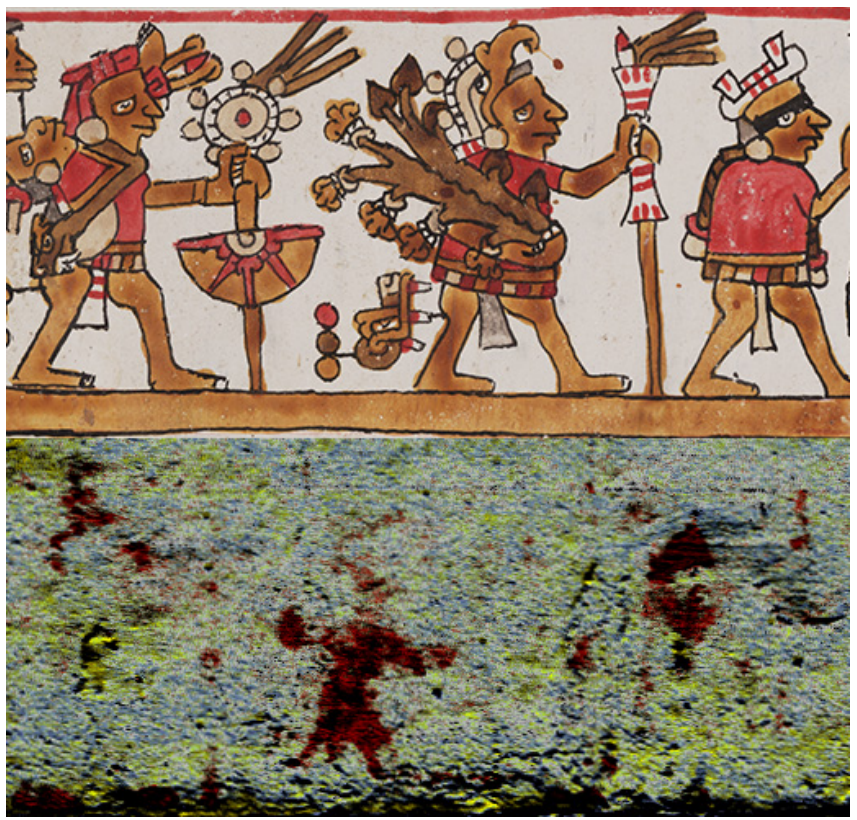

Figure 5. Walking people found on the front of the codex Añute (page 9) compared with figures found in the palimpsest (page 6), (c) The Bodleian Libraries, University of Oxford.

The severely worn page 3 has yielded a number of partially interpreted features as well, most of which seem to be place signs containing the glyphs for rivers. Two examples are given in Figure 6 , as well as similar scenes in other texts. One is depicted as the cross-section of a river; the other is a cross section which is again cut in half. This image also illustrates the difficulty with secure identification of such glyphs, as their identifying components added to these glyphs can be rather complex and varied. 


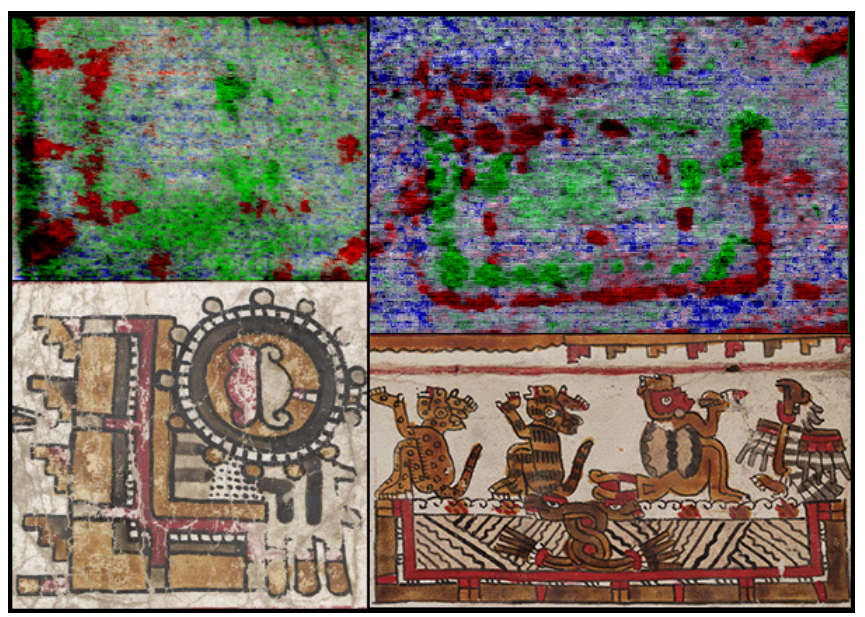

Figure 6 two examples of river place signs found on page 3 verso, compared with two river glyphs from codex Ñu Tnoo-Ndisi Nuu and Añute, (C) The Bodleian Libraries, University of Oxford.

The far right page of this document, page 1 verso, is the front cover of the known codex Añute. It is severely worn, so the reconstruction of any figures is at present not possible. On the far right of the page the traces of the reading lines can be seen, all continuing to the edge of the page. This suggests that this page was not originally the end of the document. At least one more page is needed to complete this section. Considering the general composition of the codices, which often had covers glued to their outsides, it is logical that a page is missing here. If a cover was glued to the outside of the codex, this section would have been difficult to reuse.

\section{Discussion}

\subsection{Nature of the covered codex}

As Caso (1964) already noted, there are some major differences between the known codex Añute and the texts of the palimpsest. Where the text on the front is read from bottom to top with the book held vertically, the text of the palimpsest is read in a zig-zag pattern over two pages with the book held horizontally. It is in this sense it is closer to one of the other known Mixtec codices, the codex Ñu Tnoo-Ndisi Nuu (Bodley). The lack of a complete overview of the contents makes it difficult to make statements about the content of this book with certainty. However what has been recovered thus far suggests that this codex contains information that is at least in part unique. The recovered combination of the large glyph for flint or knife and the twisted cord is a known personal name only found on one major character in the other codices (see Caso, 1979). This Lord 2 Dog is encountered in the Codices Tonindeye (Nuttall, pp 32,34) and Ñuu Tnoo-Ndisi Nuu (Bodley, pp 15-16). He is an ancestor of two lineages connected to the archaeological sites of Zaachila and Teozacualco, though there is not much known about him (Jansen and Pérez Jiménez, 2005). At this moment it cannot be ascertained if the character that takes centre stage in pages 11 and 10 verso of this palimpsest is this same person, as it has not yet been possible to reconstruct the calendar name. Scans of the adjacent pages may shed light on this, as the recognition of the same design in multiple locations makes it easier to reconstruct. It is hoped that combinations of people, place names or events can be correlated with known Mixtec history. This would allow more in depth reconstruction.

\subsection{Future directions}

There are three main ways in which the results obtained so far can be improved. First of all to interpret the codex as a whole, the rest of the pages will be scanned. In this way further connections with the already known codices may be obtained and the context of the thus far reconstructed scenes will be better understood. In order to make the yellow paint more visible, a stronger light source may be needed, as this may penetrate the gesso surface better, thus improving the chances of distinguishing the relatively similar spectral signals. In general, the intensity of the light source is kept as low as possible when investigating works of art, to prevent any damage that may be caused by it. Since these pages are covered with gesso, the intensity of the light that reaches the actual images is very low and could safely be increased. It is also possible that the sub-surface depictions are more apparent in another wavelength outside the range that has currently been used. The gesso layer may also be more transparent at another wavelength. Hyperspectral imaging in the infrared region is a candidate for further exploration.

There remains one fundamental problem in this way of interpreting the hyperspectral imaging data. Extraction of images and subsequent visual interpretation and manual reconstruction does not yet optimally utilize the possibilities of this data. It may be possible to design a routine for the automatic extraction of specific features. The numerals of the calendar signs, being simple circular shapes, are the simplest candidates for an automatic feature extraction. The calendar signs are also relatively simple as there is a limited set of possible signs, with a large number of examples present in the known codices.

\section{Conclusion}

Hyperspectral imaging has proven to be the best method for the recovery of the images in the codex Añute palimpsest. The colour most easily recovered is the cochineal red. The other colours, mostly yellow and orange, require more detailed analysis and may be better recovered when a stronger light source is used in the image acquisition. Although the reconstruction is still in progress, it is clear that the text of the palimpsest is different both in style and content, from the known codex Añute. It also seems to differ significantly from the other four known Mixtec codices. Further scans and analyses are needed to complete the overview of the texts. After complete reconstruction, a process of interpretation of the text can start. As the history of translation of the known codices and the continued discussions about certain details illustrates, this will be a long process. These first scan results however show the potential of this document for the recovery of additional information on Mixtec history and archaeology.

\section{Acknowledgement}

We express our gratitude to the Netherlands Organisation for Scientific Research (NWO) for funding this research as part of their Science4Arts program, project no. 323-54-006. This publication 
was also made possible by the use of equipment funded by the John Fell Oxford University Press (OUP) Research Fund.

\section{References}

Dark, P., Plesters, J., 1958a. The Palimpsests of Codex Selden; Recent Attempts to Reveal the Covered Pictographs, 33d Annual International Congress of Americanists, pp. 530-539.

Maldonado Alvarado, M., Maldonado Alvarado, B., 2004. La sabiduría de las pieles, Conaculta-INAH, Mexico.

Alvarez, T., 1966. Informe sobre la piel, in: Caso, A., Smith, M.E. (Eds.), Interpretacion del Codice Colombino, Las Glosas del Codice Colombino, Sociedad Mexicana de Antropologia, Mexico City. Jansen, M.E.R.G.N., Pérez Jiménez, G.A., 2011. The Mixtec Pictorial Manuscripts: Time, Agency, and Memory in Ancient Mexico, Brill, Leiden.

Boone, E.H., 2000. Stories in Red and Black: Pictorial Histories of the Aztecs and Mixtecs, University of Texas Press, Austin.

Zetina, S., Ruvalcaba, J., Cáceres, M.L., Falcón, T., Hernández, E., González, C., Arroyo, E., 2011. Non destructive in situ study of Mexican codices: methodology and first results of materials analysis for the Colombino and Azoyu codices, Proceedings of the 37th International Symposium on Archaeometry, 13th-16th May 2008, Siena, Italy, Springer, pp. 349-354.

Miliani, C., Domenici, D., Clementi, C., Presciutti, F., Rosi, F., Buti, D., Romani, A., Laurencich Minelli, L., Sgamellotti, A., 2012. Colouring materials of pre-Columbian codices: non-invasive in situ spectroscopic analysis of the Codex Cospi, Journal of Archaeological Science 39, 672-679.

Buti, D., 2012. Multi-technique approach for the in situ study of ancient manuscripts, Science for the Conservation of Art, Università degli Studi di Firenze, Florence.

Smith, M.E., 1973. Picture Writing from Ancient Southern Mexico; Mixtec Place Signs and Maps, University of Oklahoma Press.

Byland, B.E., Pohl, J.M.D., 1994. In the Realm of 8 Deer: The Archaeology of the Mixtec Codices, University of Oklahoma Press, Norman.

Joyce, A.A., Workinger, A.G., Hamann, B., Kroefges, P., Oland, M., King, S.M., 2004. Lord 8 Deer" Jaguar Claw" and the Land of the Sky: The Archaeology and History of Tututepec, Latin American Antiquity 15, 273-297.

Dark, P., Plesters, J., 1958b. The Palimpsest of Codex Selden: A Summary Report of Recent Attempts to Reveal the Covered Pictographic Matter, Bodleian Library, Unpublished.

Caso, A., 1964. Interpretación del Códice Selden 3135 A.2, Sociedad Mexicana de Antropologia, Mexico.

Earl, G., Martinez, K., Malzbender, T., 2010. Archaeological applications of polynomial texture mapping: analysis, conservation and representation, Journal of Archaeological Science 37, 20402050.

Grahn, H., Geladi, P., 2007. Techniques and Applications of Hyperspectral Image Analysis, Wiley.

Jolliffe, I., 2002. Principal component analysis, Wiley Online Library.

Stone, J.V., 2004. Independent Component Analysis: A Tutorial Introduction, MIT Press.

Jansen, M.E.R.G.N., Pérez Jiménez, G.A., 2007. Historia, literatura e ideología de Ñuu Dzaui: el códice añute y su contexto históricocultural, Fondo Editorial del Instituto Estatal de Educación Pública de Oaxaca, Oaxaca.

Jansen, M.E.R.G.N., Pérez Jiménez, G.A., 2005. Codex Bodley: A Painted Chronicle from the Mixtec Highlands, Mexico, The Bodleian library, Oxford.

Anders, F., Jansen, M.E.R.G.N., Pérez Jiménez, G.A., 1992. Crónica mixteca: el rey 8 venado, garra de jaguar, y la dinastía de Teozacualco-Zaachila, libro explicativo del Ilamado Códice ZoucheNuttall, Fondo de Cultura Económica, Mexico.
Caso, A., 1979. Reyes y Reinos de la Mixteca: Diccionario Biografico de los Senores Mixtecos, Fondo De Cultura Economica, México. 